\title{
Projeto Cidadão Ambiental Mirim: contribuiç̧ões à Educação Ambiental no ensino fundamental
}

\author{
Environmental little citizen project and environmental education for \\ elementary school
}

Dalva Simone Strapasson Dias* Universidade Federal do Paraná

Sônia Maria Marchiorato Carneiro** Universidade Federal do Paraná

Resumo $\mathrm{O}$ trabalho tem por objetivo socializar os resultados da pesquisa que analisou as contribuições do Projeto "Cidadão Ambiental Mirim", no desenvolvimento da Educação Ámbiental (EA), nos anos iniciais do ensino fundamental, no município de Colombo-PR. O referencial teórico teve como pressuposto a importância da formação cidadã do educando, comprometido com uma viável sustentabilidade socioambiental. A pesquisa qualitativa, diagnóstico-avalitativa, levantou dados por meio de observações participantes, análise documental, entrevistas e questionários com docentes, equipes pedagógicas e alunos; o tratamento dos dados embasou-se no método de análise de conteúdos. O estudo revelou que o Projeto tem potencial educativo para estimular a formação cidadã dos educandos, precisando avançar sob o foco da EA crítica, em relação ao seu desenvolvimento prático e na formação dos educadores, na perspectiva de uma educação socioambiental cidadã.

PALAVRAS-ChaVE: Educação ambiental; Consciência socioambiental cidadã; Anos iniciais do Ensino fundamental.

Abstract The article aims at socializing a research results on the contributions of the "Environmental Little Citizen" Project for the development of Environmental Education (EA), under the citizenship focus, in the elementary years within three public schools in Colombo, PR, Brazil. The basic assumption was the importance of citizen education committed to socio-environmental sustainability. The qualitative diagnostic-evaluative study inquired teachers, pedagogical personnel and pupils about conceptual aspects and procedures of the Project through participant observation, documental analysis, interviews and questionnaires; the data underwent the content-analysis treatment method. Thus, the Project had its educational potential positively ascertained, needing theoretic-methodological improvement and better integration between its main Team and school personnel; as well, it is urgent advancing the preparation of professionals involved, under the focus of civic and environmental education.

KEYWORDS: Environmental education; Environmental awareness; Early years of elementary school. 


\section{Introdução}

Este trabalho visa a socializar pesquisa sobre o Projeto Cidadão Ambiental Mirim, da Secretaria Municipal do Meio Ambiente (SEMMA) de Colombo-PR, no ensino fundamental. A diretiva do trabalho partiu da questão: - como este projeto vem contribuindo para o desenvolvimento da consciência socioambiental cidadã pelos sujeitos-alunos, nos anos iniciais do ensino fundamental da Rede Pública de Colombo? A justificativa da pesquisa decorreu do objetivo da SEMMA ampliar o projeto para outras escolas, buscando avaliar seu potencial quanto à EA em conexão com a realidade escolar.

O estudo partiu da EA enquanto dimensão fundamental da educação, em comprometimento com a formação cidadã socioambiental do educando, em vista da sustentabilidade dos lugares de vida. Nessa linha, o artigo 13, parágrafo IV, das Diretrizes Curriculares Nacionais para a EA, enfoca como um dos seus objetivos "[...] incentivar a participação individual e coletiva, permanente e responsável, na preservação do equilíbrio do meio ambiente, entendendo-se a defesa da qualidade ambiental como um valor inseparável do exercício da cidadania [...]”. (BRASIL, 2012, p. 04).

Essa perspectiva de educação para cidadania ambiental implica educadores e educandos refletindo sobre ações pela qualidade de seus ambientes e a prática de deveres e direitos a um ambiente sadio e sustentável. Emerge daí a importância do envolvimento das escolas com a realidade local, em vista da formação de sujeitos-alunos engajados na transformação das relações da sociedade com o meio ambiente.

Desde 2003 a SEMMA realiza atividades de EA em parceira com a Secretaria Municipal de Educação (SEMED), apoiando as escolas com materiais informativos sobre aspectos ambientais e desenvolvendo projetos, compreendendo a formação de educadores em EA.

No início de 2010 a equipe de EA da SEMMA iniciou projeto piloto em 03 escolas para sensibilizar alunos, pais e moradores dos entornos escolares quanto ao cuidado e respeito pelo meio ambiente; foram constituídos grupos de educadores mirins por alunos de $4^{\circ}$ e $5^{\circ}$ anos - cerca de 100 crianças, 05 professoras e equipes pedagógicas. O nome do Projeto, "Cidadão Ambiental Mirim”, foi escolhido pelos alunos e professoras participantes, mediante votação nas escolas.

Nos meses letivos de 2010-2011, realizaram-se 12 encontros nas escolas e a equipe de EA orientou os professores e os alunos, em conversas, com textos de apoio, atividades extraclasses, jogos educativos e oficinas no viveiro da SEMMA: o foco de trabalho foram características naturais do ambiente de Colombo (flora, fauna, relevo e hidrografia) e situações de preservação e/ou degradação. Dentre os materiais de apoio foi distribuída, aos alunos e professores, uma cartilha de EA, com noções conceituais sobre os temas explorados, propostas de ações conjuntas nos bairros e atividades lúdicas.

Após um ano de ação com as escolas, a equipe de EA avaliou a intenção dos docentes e equipes pedagógicas quanto à continuidade do projeto, a qual foi con- 
firmada; assim a SEMMA apoiou a presente pesquisa, visando à ampliação do projeto a outras escolas.

Verificaram-se indicadores da fragilidade socioambiental dos lugares onde estão as escolas: atividades de alto impacto com a exploração industrial de calcário, que resulta em problemas de saúde e destruição do patrimônio espeleológico (Escola A); agricultura convencional com uso de agrotóxicos e fertilizantes em áreas de mananciais e de preservação ambiental gerando desaparecimento de fontes e poluição do Aquífero Karst (Escola B); e a ocupação urbana rápida e desordenada - derrubada de áreas verdes e mata ciliar, assoreamento de córregos e contaminação de recursos hídricos de nascentes - trazendo consequências à paisagem e qualidade de vida da população (Escola C).

A conscientização dos educandos sobre tais problemas demanda uma educação para a cidadania socioambiental, pois é nessa perspectiva que uma comunidade terá condições de tomar posição e desenvolver ações para superar problemas e assegurar a sustentabilidade dos bens naturais e da sociedade.

Sob esse pressuposto e da posição da SEMMA em apoiar a inserção da EA nas escolas, via o Projeto Cidadão Ambiental Mirim, buscou-se conhecer com mais profundidade seus efeitos no cotidiano escolar. Assim, o objetivo da pesquisa foi: avaliar as contribuições do projeto no desenvolvimento da EA sob o foco da cidadania local, nos anos iniciais do ensino fundamental, nas escolas participantes.

\section{Desenvolvimento}

\section{Discussão teórica da pesquisa}

\section{Educação Ambiental e formação cidadã}

O item enfoca a importância da EA como estratégia prioritária na formação de sujeitos conscientes e atuantes frente a questões socioambientais, para exercerem a cidadania em prol da realidade ambiente. A construção do saber ambiental pelos alunos parte de um processo contínuo de reflexão sobre seus lugares de vivência. De acordo com Freire (1980, p. 36), "[...] na medida em que o homem, integrado em seu contexto, reflete sobre este contexto e se compromete, constrói a si mesmo e chega a ser sujeito". Para um efetivo trabalho de EA, são fundamentais práticas pedagógicas reflexivas sobre o cotidiano escolar, oportunizando situações de aprendizagem e estimulando os alunos a participar da comunidade por ações cidadãs, vinculadas ao pertencimento local como força coletiva.

Nesse foco, as relações estabelecidas no campo educativo são práticas pedagógicas de exercício da cidadania, visando ao desenvolvimento de atitudes valorativas em prol do bem comum. Nesta perspectiva, Santos (2005, p. 99) afirma que "[...] é necessário ensinar e aprender a cidadania." A autora entende a cidadania como conquista apoiada na autonomia, a ser interiorizada e exercitada constantemente por todos, como projeto de vida. Sob tal ótica, defende a cidadania democrática e participativa, 
tendo por pré-requisito os "direitos cognitivos" - direitos à educação, à comunicação e ao aprendizado no longo da existência. É uma cidadania do respeito às identidades socioculturais de grupos e comunidades, favorecendo a diversidade construída nas relações sociais - uma cidadania em que "[...] direitos, deveres e responsabilidades suportam-se de forma mútua, recíproca e solidária [...]"; na qual, cada cidadão seja atendido em suas necessidades pela sociedade, bem como colocar-se à disposição desta; uma cidadania, pois, que assume novos significados "[...] culturais e identitários em contextos ambientais das relações sociais; [...] e que nos vincula à complexa teia da vida, entrelaçando presente, passado e futuro".

Uma formação cidadã responsável demanda que os sujeitos-alunos, nos seus níveis de aprendizagem, compreendam as questões do meio ambiente, tanto em relação a problemas quanto a alternativas de sustentabilidade. Torna-se necessária uma prática escolar que os ajude a apreender a dinâmica complexa da realidade; pois a problemática socioambiental pressupõe um saber relacional, a partir da ação-reflexão-ação, para entendimento da causalidade múltipla e interdependência dos diferentes processos envolvidos. Segundo Lima (2002, p. 116), a compreensão de EA frente à realidade complexa, pressupõe "[...] a capacidade de aprender, criar e exercitar novas concepções e práticas de vida, de educação e de convivência - individual, social e ambiental". Tal aprendizado tem importância central na relação de educação e sustentabilidade socioambiental, pois “[...] o tipo de vida, de educação e de sociedade que teremos no futuro vai depender da qualidade [...] dos processos de aprendizagem que formos capazes de criar e exercitar individual e socialmente".

\section{A importância dos projetos de EA em parceria comunitária}

A Metodologia de Projetos é uma estratégia pedagógica fundamental no trato das questões socioambientais, enquanto atividade-ponte, que conecta o diálogo entre o cotidiano escolar e seu entorno. A mais, essa metodologia facilita o trabalho interdisciplinar, como modo novo de organizar e produzir conhecimentos, interligando "[...] conhecimentos disciplinares e o diálogo dos saberes especializados com saberes não científicos". (CARVALHO, 2004, p. 121); viabiliza pois, a superação da fragmentação do conhecimento por uma abordagem relacional da realidade ambiente na compreensão da complexidade das interdependências dos fenômenos, naturais e sociais e entre eles.

Segundo Alvarez Leite (1996, p. 02), tal metodologia possibilita pensar situações-problema da comunidade dos entornos escolares, abrindo perspectivas de ensino e aprendizagem, no pressuposto de que é "[...] impossível separar os aspectos cognitivos, emocionais e sociais presentes nesse processo [...]". Esta orientação implica levantar necessidades comunitárias, visando a construir laços de comprometimento e responsabilidade dos sujeitos com a realidade. A cooperação das diferentes instituições com a escola é fundamental na efetivação do processo educativo da EA.

O trabalho com projetos de EA envolve novas estratégias para a compreensão dos temas socioambientais, para superar uma concepção de ensino e de aprendizagem como transmitir-memorizar conhecimentos. Reigada e Tozoni-Reis (2004, 
p. 157) enfocam a "aprendizagem significativa", destacando-a como referência teórico-metodológica para as ações educativas ambientais. Para as autoras, "[...] quando a aprendizagem é significativa, [...] as novas informações, [...] adquirem significado e são integradas à estrutura cognitiva de maneira não-arbitrária [...]”. A atividade intelectual nessa perspectiva passa a ser compreensão-apropriação ativa e consciente dos conhecimentos. As autoras ainda colocam a importância de planejar o ensino visando a experiências afetivas positivas, a fim de ter o conhecimento sentido de realidade na vida dos educandos.

Os projetos de EA também corroboram a interação com a comunidade, que é o lugar de vivência, onde as pessoas se relacionam e se organizam em função de interesses e ideais; formam suas famílias, adquirem conhecimentos e produzem cultura. Segundo Demo (2009, p. 59), a identificação cultural motiva um grupo à participação num projeto concreto, pois “[...] não há projeto comum de vida, assumido em coesão comunitária, sem identidade do grupo". Assim, projetos de EA são instrumentos ao exercício da cidadania ativa, tanto para quem os idealiza como para a comunidade que neles se engaja.

\section{A criança e a cidadania}

A educação será efetiva no desenvolvimento da criança, se esta for reconhecida como cidadã, sujeito de direitos e criadora de cultura. Segundo Kramer (1999, p. 02), o entendimento de quem são as crianças enquanto "[...] cidadãos de pouca idade, sujeitos sociais e históricos, criadores de cultura - é condição para que se atue no sentido de favorecer seu crescimento e constituição, buscando alternativas para a educação [...]". Há que se reconhecer o saber das crianças e oferecer-lhes "[...] atividades significativas, onde adultos e crianças têm experiências culturais diversas, em diferentes espaços de socialização".

Nessa perspectiva, a EA constitui uma dimensão do processo educativo, como ciclo contínuo de conhecimento e aprendizagem das questões relativas ao meio ambiente, desde a escolarização inicial. Portanto, a EA tem a finalidade de contribuir para as crianças desenvolverem valores e atitudes cidadãs: o cuidado com o meio onde vivem, já como proteção e sustentabilidade do Planeta. Sob este foco, é papel da escola apoiar as crianças, a partir do conhecimento, na vivência de valores para uma vida adulta cidadã - de solidariedade, cooperação, honestidade e responsabilidade.

Pela experiência escolar, as crianças começam a participar da vida em sociedade, a construir sua autonomia e a exercer a cidadania: deparam-se com o público e constroem o significado de coletivo, compartilhando tempos, espaços e objetos; começam a perceber a convivência grupal e a interagir com bens e linguagens. Destaca-se, pois, a escola em articulação à comunidade, valorizando o potencial formativo dos espaços não-escolares, assumindo a cultura local e seus valores, com participação de todos - educadores, educandos e famílias - no trabalho escolar.

Segundo Herculano (1995, p. 01), ao "educar para a cidadania", há que se romper a indiferença e o individualismo e ressaltar o caráter comunitário do processo 
educacional, revelando "[...] o quanto ele deve estar entrelaçado com os objetivos e valores sociais que visem à dignidade humana e o respeito à vida [...]". Uma pessoa educada para ser cidadã é "[...] a que pensa, reflete, recebe e transmite informações e aprende a se pôr em ação juntamente com os outros e com eles se organizar para alcançar o bem comum".

Nogueira (2009, p. 47), com base em Freire, afirma que crianças e adolescentes “[...] não só aprendem, como também ensinam. [...] Ensinam pelo que propõem, pelo que defendem, pelo que acreditam, pelo que vivem”. Sob esta ótica, o aluno é um "sujeito atuante" no universo escolar, ajudando a construir "a própria identidade da escola". Esta perspectiva concebe a criança como sujeito capaz: pensa, conhece, atua e modifica o que está a sua volta. Com razão, $\operatorname{Kramer}(2006$, p. 811) põe: “[...] o tempo da infância é o tempo de aprender e de aprender com as crianças, numa perspectiva da educação em que o outro é visto como um eu [...]".

É neste contexto que se justifica pensar em "educadores ambientais mirins" enquanto educandos em formação que, a partir do aprendizado de ser "cidadão ambiental" em seus espaços de vida, terão condições de compreender a influência de suas atitudes e comportamentos sobre os outros, entre os quais os adultos que convivem com eles, para uma mudança de postura em relação ao seu ambiente. Portanto, é preciso que a escola crie condições de exercício da cidadania desde a infância, para ir formando os "educadores ambientais mirins".

Cabe trazer a posição de Tavares (2001, p. 01), ao afirmar que a escola deve formar crianças e jovens construtores da sociedade, capazes de viver em seus espaços sociais uma cidadania consciente, referenciada e atuante; é tarefa que exige uma prática educativa participativa, dialógica e democrática, dado que "[...] educar na, para e pela democracia implica [...] criar espaços de decisão e de vivência de princípios éticos, de solidariedade, de justiça, de diálogo". A escola deve humanizar a partir da socialização e construção do conhecimento criterioso, analítico e problematizador, no exercício de uma cidadania interviniente nas questões socioambientais.

\section{A formação de educadores ambientais}

A EA, na formação de professores, vem sendo recomendada desde Estocolmo (1972), em eventos nacionais e internacionais sobre Meio Ambiente e EA, bem como nos documentos históricos que embasam a EA brasileira. A Lei 9795/99 e as Diretrizes Curriculares Nacionais para a EA (2012) destacam a necessidade da formação dos docentes. Para Guerra e Guimarães (2007), é papel da universidade promover condições, na formação inicial e continuada de professores, para que a EA seja inserida na prática escolar a partir de projetos político-pedagógicos e da organização coletiva de professores e equipes pedagógicas. Leff (2001), igualmente, enfoca que a universidade desempenha papel essencial na formação ambiental dos profissionais do ensino e, daí, há necessidade de abertura curricular aos paradigmas teórico-metodológicos do saber ambiental, demandando novos conteúdos, estratégias de investigação e métodos pedagógicos. Segundo o autor, a formação docente em EA implica 
[...] novas orientações e conteúdos; novas práticas pedagógicas onde se plasmem as relações de produção de conhecimentos e os processos de circulação, transmissão e disseminação do saber ambiental. Isto coloca a necessidade de incorporar os valores ambientais e novos paradigmas do conhecimento [...]. (LEFF, 2001, p. 251).

A formação de educadores ambientais urge uma reorientação epistemometodológica dos currículos e programas de formação, para a superação da visão tradicional e fragmentada de meio ambiente por uma compreensão da totalidade e complexidade dos contextos espácio-temporais. Tristão (2007) considera que, para conduzir a formação de professores em EA, dentro de uma perspectiva crítica, é preciso envolver entidades formadoras (instituições de ensino superior) e de atuação dos profissionais da educação (escolas, secretarias, instituições não governamentais) no comprometimento articulado com a EA, entre a formação inicial e continuada, segundo especificidades regionais e locais; e ainda considerar outros espaços diversificados de formação contínua, como oficinas, seminários, grupos de estudo, eventos e atividades de extensão.

É primordial que as instituições de formação de educadores valorizem temas relacionados à ética cidadã, em termos de práticas sociais do exercício de deveres e direitos, visando à qualidade dos ambientes de vida. Isso implica uma formação docente emancipatória e transformadora (FREIRE, 1980).

\section{Metodologia e resultados da pesquisa de campo}

Segundo objetivo da pesquisa, optou-se pela modalidade de investigação qualitativa, em forma de um estudo diagnóstico-avaliativo. Conforme Lüdke; André (1986, p. 18), “[...] o estudo qualitativo [...] se desenvolve numa situação natural, é rico em dados descritivos, tem um plano aberto e flexível e focaliza a realidade de forma complexa e contextualizada." Os dados de campo foram levantados mediante observação participante, entrevistas semi-estruturadas e questionários com professores (05), coordenadores e diretores (05); e com os alunos por entrevistas semi-estruturadas coletivas (13, correspondendo a 10\% do total de alunos das três escolas participantes da pesquisa); e ainda análise documental do Projeto Político Pedagógico das escolas, do planejamento de ensino, das cartilhas produzidas pela equipe de EA e da proposta do Projeto.

O tratamento de dados embasou-se no método da análise de conteúdos, segundo Bardin (1977), nas etapas: - pré-análise do material coletado, com leitura global das informações de entrevistas e registros de observação e dos documentos; - exploração dos dados, estabelecendo-se categorias de conteúdos temáticos para exame dos significados dos dados; - e análise interpretativa dos mesmos, com base no referencial teórico e de outras fontes pertinentes - considerando-se, para cada aspecto da pesquisa, o conjunto dos dados.

Os dados levantados, com as docentes e equipes pedagógicas, relacionam-se ao entendimento de meio ambiente, Educação Ambiental e cidadania; e ao desenvolvimento do Projeto nas escolas. Quanto ao meio ambiente, mais da metade das entrevistadas (06) trouxe uma visão naturalista, desconectada do social e antropocêntrica 
- dado que os bens naturais apenas servem aos humanos, sem valor intrínseco; duas expressaram visão genérica de meio ambiente; e outras duas uma visão mais elaborada sob a perspectiva socioambiental, pois tinham alguma formação em EA. Tais resultados mostram deficiência formativa quanto à temática ambiental.

Todas docentes apresentaram uma compreensão de EA relacionada ao desenvolvimento da conscientização de cuidado para com o meio ambiente: - quatro professoras mostraram uma visão conservacionista/naturalista de EA; e três, de cuidado do ambiente geral, sem base teórico-metodológica e tendendo a uma prática de senso comum, centrada em comportamentos individuais; - e três evidenciaram visão mais elaborada de EA, vinculada à formação em valores de responsabilidade e sustentabilidade socioambiental, mas sem entendê-la na perspectiva da educação cidadã.

Quanto à cidadania, para a metade das educadoras (05), era o exercício de direitos e deveres enquanto participação na sociedade; e a outra metade expressou-a como um estado de bem-viver, consigo e em sociedade. No primeiro caso, o entendimento relaciona-se a aspectos da cidadania individual, precisando ampliar-se como participação organizada na sociedade, para transformações necessárias nos ambientes locais. Para desenvolver uma EA crítica, importa que o pessoal escolar considere as duas dimensões de cidadania - individual e social - em vista da formação cidadã dos alunos, baseada na compreensão de ações coletivas para mudanças no lugar de vida e no mundo.

Outro dado levantado foi a predominância dos deveres sobre os direitos de cidadania, evidenciando uma cultura subalterna: a superação dessa visão se dará à medida que os sujeitos, pela educação emancipatório-cidadã, forem capazes de compreender a realidade histórico-cultural como criada pelo homem, podendo ser transformada e, sob essa ótica, entender o sentido dos direitos e deveres frente aos problemas socioambientais. No segundo caso, os sujeitos trazem uma perspectiva idealista e apolítica de cidadania, sem relação ao exercício de direitos e deveres, tão pouco a uma participação comunitária de mobilização conjunta.

No que se refere ao significado e importância do Projeto para as escolas, a maioria dos sujeitos (09), considerou que ajudava na conscientização das crianças e dos adultos sobre o meio ambiente; dois sujeitos destacaram a ação concreta do Projeto na comunidade; observou-se que o significado do mesmo, vinha ao encontro do seu entendimento de EA, enquanto desenvolvimento da conscientização de cuidado com o meio ambiente. Ao explicar a importância do Projeto nas escolas, destacaram o cuidado pelo ambiente em conexão aos lugares de vida dos alunos. Nesse sentido, a importância do Projeto relacionava-se à finalidade e aos objetivos do mesmo, ou seja, que os educandos se conscientizassem quanto aos cuidados com os ambientes de vida e ajudassem as pessoas a cuidar desses lugares. No entanto, os sujeitos da pesquisa mostraram visão acrítica e despolitizada do Projeto quanto à formação cidadã dos alunos, sobretudo no bairro onde viviam; isso decorreu, provavelmente, da falta de formação ambiental das educadoras, bem como da carência de orientação, por parte da equipe de EA da SEMMA. O documento do Projeto também carece de fundamentação teórico-metodológica nesse enfoque educacional; apresenta ideias válidas, entretanto fragmentadas e mais na linha da EA conservadora/tradicional. 
Em relação à prática do Projeto nas escolas, foram analisados três aspectos: valores, atitudes e habilidades a serem desenvolvidos pelas crianças; conteúdos ou temáticas; e estratégias metodológicas para o alcance da cidadania ambiental mirim. Sobre valores, atitudes e habilidades, todas as professoras (05) apontaram como importantes: responsabilidade, solidariedade, cuidado, amor e respeito pelo meio natural e pelo próximo, mas sem conexão com cidadania; e duas ainda destacaram as habilidades de observação, percepção, curiosidade, pesquisa e do senso crítico para análise interpretativa da realidade ambiente. Observou-se, porém, em sala de aula, um trabalho espontaneísta e esporádico quanto a esses valores, atitudes e habilidades; além do que, no planejamento das docentes e no registro diário das atividades, não apareceram essas intenções - apenas uma docente estabeleceu relações nas aulas com cidadania. Esses resultados revelam a deficiência da EA no processo escolar. O Projeto prevê o desenvolvimento de valores e atitudes ambientais, mas que só serão alcançados em um trabalho contínuo nas escolas, não somente quando ocorrem as atividades previstas; com exceção de duas docentes, as demais veem o Projeto como um trabalho pontual.

Quanto a conteúdos e temáticas pelo desenvolvimento da cidadania socioambiental, as docentes citaram cuidados com o meio natural, o lixo, os agrotóxicos, a poluição em geral e conteúdos da Carta da Terra e da legislação ambiental. Estes conteúdos relacionam-se aos problemas socioambientais de Colombo, estão previstos nas Diretrizes Curriculares Municipais e foram trabalhados pelo Projeto. São conteúdos válidos para se desenvolver uma EA crítica em prol da cidadania. Mas observou-se nas aulas que, após as atividades do projeto, nem sempre era dada continuidade ao tratamento desses conteúdos pelas docentes - quando retomados, era de forma aligeirada, mais no sentido de fixá-los e não como reflexão.

Todas as docentes consideraram positivas as estratégias metodológicas do Projeto - os recursos didáticos, as orientações e saídas de campo. No desenvolvimento de conteúdos, a equipe de $\mathrm{EA}$, inicialmente conservacionista, com a pesquisa passou a tratá-los sob o enfoque socioambiental; mas dada a falta de preparo referencial da equipe, as atividades ficaram em nível mais de informações socioambientais do Município do que de reflexão sobre os problemas específicos de cada escola, na perspectiva do exercício da cidadania.

O planejamento do Projeto com as escolas vem sendo incipiente, não tendo ainda sido incorporado como uma estratégia metodológica para trabalhar a EA, mas como uma atividade pontual e complementar ao currículo escolar, de responsabilidade da SEMA. No tocante às melhorias do Projeto, evidenciou-se necessária mais disponibilidade da equipe de EA para atuar nas escolas, orientando os docentes no encaminhamento dos conteúdos e dando suporte de recursos didáticos; também foi posta a necessidade do planejamento em conjunto, entre equipe e as escolas.

Todos os alunos afirmaram gostar das atividades do Projeto, pois, aprendiam sobre meio ambiente, conheciam outros lugares, faziam atividades diferentes e podiam ensinar aos outros o que aprendiam; tais respostas também refletiram o entendimento do que é ser cidadão ambiental mirim: quase todos entendiam que é cuidar da natureza e do ambiente em geral; cinco alunos ainda enfocaram que é ensinar crianças 
e adultos sobre a importância do cuidado com o ambiente. Esses resultados indicam que o Projeto tem conseguido sensibilizar as crianças e seus familiares, evidenciando que os alunos já atuam em seus espaços, buscando influenciar atitudes e comportamentos dos adultos, com quem convivem, para mudança de postura sobre meio ambiente. No entanto, trazem colocações mais prescritivas, em termos de deveres e não de direitos. $\mathrm{O}$ fato dos alunos estarem cientes de seus deveres, com a realidade ambiente, é apenas ponto de partida para desenvolverem a consciência de sua formação cidadã. Para isso, precisam avançar na conscientização socioambiental, no rumo dos direitos sócio- comunitários - para além da identificação de problemas e mudanças de comportamentos individuais.

Quanto à compreensão de meio ambiente, todos os alunos consideraram sinônimo de meio natural, sendo que quatro incluíram nele o homem; este entendimento reflete a visão da maioria das docentes. A propósito do entendimento de cidadania, a maioria (11) trouxe aspectos relacionados aos deveres; constatou-se a ausência do entendimento de cidadão na sua relação com direitos. Entretanto, questionados se já tinham ouvido falar sobre direitos do cidadão, também a maioria (09), conhecia alguns direitos, como: direito a um ambiente saudável, à educação, saúde, moradia, saneamento, comunicação, alimento e ao voto; evidenciou-se que não tinham uma compreensão referenciada dos seus direitos.

Em termos de mudanças necessárias no bairro onde moravam, indicaram: cuidados com o lixo na rua, nos rios, no seu destino final e reciclagem; com o esgoto lançado nos rios; com a poluição do ar pelas firmas e segurança etc. Os alunos tinham percepção dos problemas e visualizaram soluções ao indicarem quem seria responsável pela melhoria do bairro, sendo que apenas dois não souberam responder. Mais da metade deles (08) considerou que todos os moradores do bairro, incluindo as crianças, são responsáveis pelas mudanças; três também enfocaram a responsabilidade em conjunto, com o governo e órgãos e, três outros, a responsabilidade somente do governo; excetuada esta visão assistencialista e paternalista, os outros demonstraram estarem despertando o senso de cidadania ao destacar a necessidade de todos atuarem pela melhoria dos ambientes de vida; entretanto, prevalece a ideia do dever, sem conexão ao direito de reivindicar os bens de cidadania.

Com base neste diagnóstico, o Projeto precisa rever as práticas educativas, de modo que o exercício de direitos e deveres não se restrinja a discursos desvinculados da realidade ambiente de Colombo. Assim, é fundamental o desenvolvimento da EA crítica na formação do cidadão ambiental mirim e, dessa maneira, ajudar os alunos a raciocinar sobre os problemas socioambientais de sua realidade e buscar possíveis soluções e intervenções para superar condições indesejáveis nas comunidades de Colombo.

\section{Considerações finais}

Os resultados da pesquisa evidenciaram o potencial educativo do Projeto. Ainda que seja novo, já vem alcançando resultados significativos, especialmente por parte dos "educadores ambientais mirins", que se mostraram engajados na defesa de um ambiente saudável, buscando influenciar o comportamento adulto para a mudança 
de atitudes quanto ao meio ambiente. Neste horizonte, o Projeto constitui um instrumento no avanço da conscientização socioambiental cidadã dos alunos e da comunidade escolar.

Com base nos resultados, cabem algumas indicações de avanço do Projeto, como instrumento pedagógico para trabalhar a EA nas escolas de Colombo:

a) rever a proposta documental, em seus fundamentos teórico-metodológicos, bem como em relação ao desenvolvimento prático na perspectiva da EA crítica, estruturando-se junto a cada escola uma unidade relacional do Projeto com o planejamento escolar, quanto a objetivos, conteúdos, atividades, avaliação e cronograma;

b) repensar estratégias de encaminhamento do Projeto, a partir dos interesses das escolas e em conexão com os problemas socioambientais vivenciados pelos educandos e pelas comunidades dos entornos escolares, de modo a superar um trabalho pontual e acrítico;

c) planejar a formação dos professores sob o foco da educação socioambiental cidadã, em vista de uma fundamentação teórico-metodológica aprofundada, que lhes oportunize repensar suas práticas no compromisso de formar alunos cidadãos ambientais mirins;

d) estimular a inserção efetiva do Projeto e da EA no PPP das escolas, sob a perspectiva da consciência cidadã em prol da sustentabilidade socioambiental de Colombo.

\section{Referências}

ALVAREZ LEITE, L. H. Pedagogia de projetos: intervenção no presente. Revista Presença Pedagógica. V. 2, no 8, mar./abr, 1996. Disponível em: www.edufisescolar.files.wordpress.com/ acesso em: 23 jun. 2011.

BARDIN, L. Análise de conteúdo. Tradução L. A. Reto; A. Pinheiro. Lisboa: São Paulo: Edições 70, 1977.

BRASIL. Lei n. 9795 de 27 de abril de 1999. Dispõe sobre a educação ambiental, institui a Política Nacional de Educação Ambiental e dá outras providências. Diário Oficial da República Federativa do Brasil, Brasília, n. 79, 28 abril, 1999.

Ministério da Educação e Cultura. Resolução n. 02, de 15 de junho de 2012. Estabelece as Diretrizes Curriculares Nacionais para a Educação Ambiental. Disponível em: http://www. portal.mec.gov.br/dmdocuments/publicacao13.pdf. Acesso em: 16 ago. 2012.

Carvalho, I. C.M. A escola como projeto sócio-cultural e os projetos de trabalho na escola. In: Boletim Vida e natureza, ambiente e cultura. MEC-TV. Programa Salto para o Futuro, TV Escola. 2004

COLOMBO. Prefeitura Municipal. Secretaria de Meio Ambiente. Projeto Cidadão Ambiental Mirim. Colombo: SEMMA, 2010.03 p.

DEMO, P. Participação é conquista. 6aa ed. São Paulo, Cortez, 2009.

FREIRE, P. Conscientização: teoria e prática da libertação - uma introdução ao pensamento de Paulo Freire. 3 ed. São Paulo: Moraes, 1980. 
GUERRA, A. F.S.; GUIMARÃES, M. Educação ambiental no contexto escolar: Questões levantadas no GDP. In: Revista Pesquisa em Educação Ambiental USP. Ribeirão Preto, v.2, n. 1, jan./jun. 2007, p. 155-166.

HERCULANO, S. A consciência da solidariedade. Educador ambiental. São Paulo: Ecopress, ano II, n. ${ }^{\circ}$ 8, mar./abr. 1995.

KRAMER, S. O papel social da educação infantil. In KRAMER, Sonia; LEITE, M. I. Infância: fios e desafios da pesquisa. Campinas. Papirus, 1999.

As Crianças de 0 a 6 anos nas políticas educacionais no Brasil: Educação Infantil e/é Fundamental Educ. Soc., Campinas, vol. 27, n. 96 - Especial, p. 797-818, out. 2006. Disponível em http://www.cedes.unicamp.br.

LEFF, E. Saber Ambiental: sustentabilidade, racionalidade, complexidade, poder. Petrópolis, RJ: Vozes, 2001.

LIMA, G. F. C. Crise ambiental, educação e cidadania. In: LAYRARGUES, P. P. Castro, R. S; LOUREIRO, C. F. B. (orgs) Educação ambiental: repensando o espaço da cidadania. São Paulo: Cortez, 2002.

LÜDKE, M.; ANDRÉ, M. E. D. A. Pesquisa em educação: abordagens qualitativas. São Paulo: EPU, 1986.

NOGUEIRA, V. Educação geográfica e formação da consciência espacial cidadã no ensino fundamental: sujeitos, saberes e práticas. Curitiba, 2009. Tese (Doutorado em Educação). Universidade Federal do Paraná.

ORGANIZAÇÃO DAS NAÇÕES UNIDAS. Declaração da Conferência de ONU no Ambiente Humano. Estocolmo, 5-16 de junho de 1972. Disponível em: <www.mma.gov.br/ estruturas/agenda21/_arquivos/estocolmo.doc.>Acesso em: 31 jul. 2014.

REIGADA, C.; TOZONI REIS, M. F.C. Educação Ambiental para crianças no ambiente urbano: uma proposta de pesquisa-ação. In. Ciência \& Educação, v. 10, n. 2, p. 149-159, 2004

SANTOS, M.E. V. M. Que educação? Para que cidadania? Em que escola? Tomo II: Que Cidadania? Lisboa: Santos-Edu 2005.

TAVARES, C. Educação para a cidadania e uma cultura de paz. Texto integrante da cartilha "Construindo uma Cultura de Paz" - Recife - 2001. Disponível em: www.dhnet.org.br/. Acesso em 10/07/2011.

TRISTÃO, M. A Educação Ambiental e os espaços/tempos de formação. In: GUERRA, A.F. S; TAGLIEBER, J.E. Educação Ambiental: fundamentos, práticas e desafios. Itajaí, 2007, p. 37-51.

* Mestre em Educação pela Universidade Federal do Paraná, Curitiba, Paraná, Brasil.

** Professora doutora da Universidade Federal do Paraná, Curitiba, Paraná, Brasil.

\section{Correspondência}

Dalva Simone Strapasson Dias - Prefeitura Municipal de Colombo, Secretaria Municipal de Educação, Cultura e Esportes. Rua XV de Novembro, Centro, CEP: 83414000 - Colombo, Paraná - Brasil.

E-mail: dalvasimone@yahoo.com.br - carneiro.sonmaria@gmail.com

Recebido em 10 de maio de 2015

Aprovado em 03 de novembro de 2015 